| Clinical | Trial |

\title{
Efficacy and safety of intralesional triamcinolone acetonide in the treatment of chronic hand eczema
}

\author{
Tasnuva Ashraf, Harasit Kumar Paul, Md. Shahidullah Sikder, A. S. M. Zakaria, \\ Mohammed Saiful Islam Bhuiyan and Kaniz Shahali Reza Snigdha
}

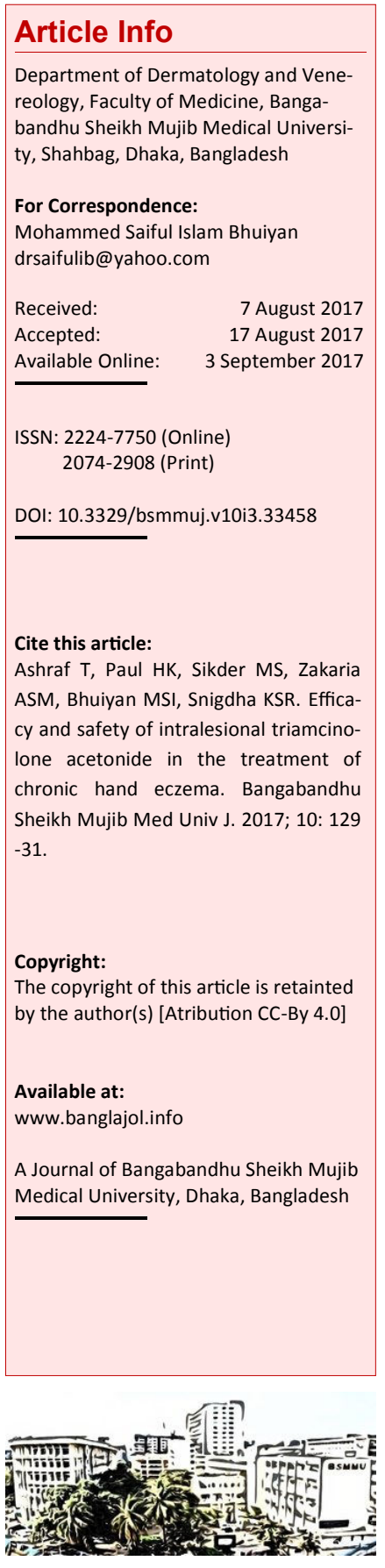

\section{Abstract}

This randomized controlled clinical trial was conducted to assess the efficacy and safety of intralesional triamcinolone acetonide in the treatment of chronic hand eczema comparing with topical clobetasol propionate. A total 60 patients of chronic hand eczema were recruited in the study. Thirty patients (Group A) were treated with intralesional triamcinolone acetonide and the rest 30 (Group B) with topical clobetasol propionate. Severity and improvement were assessed using Hand Eczema Severity Index (HECSI) score. The patients of both groups were followed up at $4^{\text {th }}$ week and $12^{\text {th }}$ week. In Group A, median HECSI score at baseline, $4^{\text {th }}$ week and $12^{\text {th }}$ week were 3, 20 and 20 respectively; whereas these scores were 54, 10 and 8 in Group B. In both groups, HECSI score was decreased gradually but the rate was higher in Group B than Group A $(\mathrm{p}<0.05)$. Thinning of skin, an adverse effect, was seen in patients of both the intralesional triamcinolone acetonide $(10 \%)$ and topical clobetasol propionate $(16.7 \%)$ groups $(p>0.05)$. The result of this study demonstrates that intralesional triamcinolone acetonide is effective and safe in treating chronic hand eczema but less effective than the topical clobetasol.

\section{Introduction}

Hand eczema or hand dermatitis is defined as an inflammation of the skin of the hands. 1 This itchy skin condition of hands usually presented with erythema, edema and occasionally vesicles in acute stage; whereas chronic hand eczema lichenification, scaling and fissures are prominent. 2 The world-wide prevalence of hand dermatitis among different racial and occupational groups ranges from 4 to $10 \% .2$

The most common causes are allergic contact dermatitis (19\%), irritant contact dermatitis $(35 \%)$, atopic dermatitis (22\%) and others such as nummular hand eczema, hyperkeratotic hand eczema, or pompholyx. 3

Among the different treatment options of hand eczema, topical corticosteroids are mostly used.t.-6 Long-term potent topical steroids are effective but the skin atrophy, infection, hypertrichosis, tachyphylaxis and adrenal suppression are among many cutaneous and systemic adverse effects. 7 Triamcinolone acetonide is a synthetic corticosteroid and effective in the treatment various skin conditions. It is a more potent derivative of triamcinolone and about eight times stronger than prednisolone. Intralesional application of corticosteroid is used to treat a dermal inflammatory process directly deliver and maintain a high concentration of the drug at the pathologic site, with less systemic absorption. 9 It avoids the thickened stratum corneum, minimize epidermal atrophy and deliver higher concentration to the site of pathology. $8-9$ Therefore, the purpose of the present study was to assess the efficacy and safety of intralesional triamcinolone acetonide in patients with chronic hand eczema comparing with topical clobetasol propionate.

\section{Materials and Methods}

It was a randomized controlled clinical trial, carried out from April to September 2014. It was conducted as a dissertation after approval of the protocol by Bangladesh College of Physicians and Surgeons (No. CPS-7/2014/DSN 2015 -010008). Sixty clinically and histopathologically diagnosed cases of chronic hand dermatitis of the duration of more than three months were selected after taking informed written consent and enrolled randomly into two groups: Group A (case) and B (control). In Group A, patients were given $0.1 \mathrm{~mL}$ injection of $40 \mathrm{mg} / \mathrm{mL}$ strength triamcinolone acetonide per square $\mathrm{cm}$ of involved area intralesionally and were repeated at 28 days interval on $4^{\text {th }}$ and $8^{\text {th }}$ week. Patients of control group were given 
topical clobetasol propionate daily 2 times for 2 weeks, then every alternate day for up to three months. Clobetasol propionate ointment (Dermovate ointment; Glaxo-Smithkline) and triamcinolone acetonide injection (Injection trialan; Ziska Pharma BD. Ltd.) were purchased from the local drug store. The effect of treatment was evaluated using Hand Eczema Severity Index (HECSI) score 10 at baseline and after treatment in $4^{\text {th }}$ week and $12^{\text {th }}$ week. The patients were scored using HECSI and were recorded.

For each location (total of both hands), the affected area was given a score from 0 to $4(0=0 \% ; 1=1-25 \%$; $2=26-50 \% ; 3=51-75 \%$ and $4=76-100 \%$ ) for the extent of clinical symptoms. Intensity of each clinical feature was given a score from 0 to $3(0=$ no feature; $1=$ mild; $2=$ moderate; $3=$ severe). Finally, the score given for the extent for each location was multiplied by the total sum of the intensity of each clinical feature (each contributing equally to the final score), and the total sum called the HECSI score was calculated, varying from 0 to a maximum severity score of 360 points.

In addition to that, adverse reactions like striae, telangiectasia, thinning of the skin, hypertrichosis were also recorded. There was no case of drop out in any treatment group.

Data were analyzed by computer with the help of SPSS Windows 17 software package. Statistical significance was set at 0.05 level and the confidence interval at $95 \%$ level. The level of significance was measured by using appropriate procedures like Chi -square test $\left(\chi^{2}\right)$, relative risk (RR) measurement, $t$ test, proportion (d) test, ANOVA tests and others where applicable. Quantitative data were expressed as mean \pm standard deviation and qualitative data were expressed as frequency distribution and percentage.

\section{Results}

The mean age of Group A (32.4 \pm 10.2 years) was higher than Group B (29.6 \pm 10.0 years) but the difference was not statistically significant $(p>0.050)$ (Table I). The male female difference between these two groups was not statistically significant $(\mathrm{p}>0.050)$. In Group A, 33.3\% patients were housewife followed by same were service holder, $20.0 \%$ were students and $13.3 \%$ were business person. In Group B, 33.3\% patients were the business person followed by $26.7 \%$ were the student, $20.0 \%$ were service holder and same were the housewife. The difference between these two groups was not statistically significant $(\mathrm{p}>0.050)$.

The initial HECSI score in Group A was 33 (12-148), at $4^{\text {th }}$ week $20(0-105)$ and at $12^{\text {th }}$ week $20(0-80)$ (Table II). In Group B, it was 54 (30-152) initially, then $10(0-34)$ and $8(0-49)$ at $4^{\text {th }}$ and $12^{\text {th }}$ week

\begin{tabular}{|c|c|c|}
\hline \multicolumn{3}{|c|}{ Table I } \\
\hline \multicolumn{3}{|c|}{$\begin{array}{l}\text { Distribution of age, gender and occupation of } \\
\text { the patients }\end{array}$} \\
\hline & $\begin{array}{c}\text { Group } A \\
(\%)\end{array}$ & $\begin{array}{c}\text { Group B } \\
(\%)\end{array}$ \\
\hline \multicolumn{3}{|l|}{ Age (years) } \\
\hline$\leq 20$ & 13.3 & 23.3 \\
\hline $21-30$ & 33.3 & 26.7 \\
\hline $31-40$ & 33.3 & 43.3 \\
\hline$>40$ & 20.0 & 6.7 \\
\hline Mean \pm SD (Year) & $32.4 \pm 10.2$ & $29.6 \pm 10.0$ \\
\hline \multicolumn{3}{|l|}{ Gender } \\
\hline Male & 46.7 & 66.7 \\
\hline Female & 53.3 & 33.3 \\
\hline \multicolumn{3}{|l|}{ Occupation } \\
\hline Student & 20.0 & 26.7 \\
\hline Service & 33.3 & 20.0 \\
\hline Business & 13.3 & 33.3 \\
\hline Housewife & 33.3 & 20.0 \\
\hline
\end{tabular}

Table II

HECSI score before treatment and after treatment in study patients

\begin{tabular}{|lccc|}
\hline $\begin{array}{l}\text { HECSI } \\
\text { score }\end{array}$ & \multicolumn{2}{c}{$\begin{array}{c}\text { Median } \\
\text { (Min-Max) }\end{array}$} & $\begin{array}{c}\text { p } \\
\text { value }\end{array}$ \\
\hline Group A & Group B & \\
\hline & 33 & 54 & 0.001 \\
After 4 & $(12-148)$ & $(30-152)$ & \\
weeks & 20 & 10 & 0.003 \\
After 12 & $(0-105)$ & $(0-34)$ & \\
weeks & 20 & 8 & 0.001 \\
\hline
\end{tabular}

Mann-Whitney U-test is done to measure the level of significance

respectively. In both groups, HECSI score was decreased gradually but the rate was higher in Group B than the Group A. In each follow-up, the difference between two groups was statistically significant $(\mathrm{p}<0.050)$.

Thinning of skin was seen in $10.0 \%$ patients of Group A and 16.7\% patients in Group B. Difference between these two groups was not statistically significant $(\mathrm{p}>0.050)$.

\section{Discussion}

The current study was conducted to compare the efficacy intralesional triamcinolone acetonide with topical clobetasol propionate in the treatment of chronic hand eczema. In both groups, HECSI score decreased gradually but the rate was higher in 
group B than A. In each follow-up the difference between two groups was statistically significant $(\mathrm{p}<0.050)$ (Table III).

It has been well established that topical steroids are the mainstay of the pharmacological treatment of hand eczema.5,11 Long-term potent steroids are very effective; however, the adverse effects like skin atrophy, tachyphylaxis, and adrenal suppression are well-known and after a few weeks of twice daily use it is recommended to use them on every alternate day or twice in a week.? Similar to the present study Möller, et al (1983) compared longterm, intermittent maintenance treatment of chronic hand eczema with clobetasol propionate comparing other topical steroid and have found that the dermatitis of $90 \%$ of these patients have been cleared.12 No previous study has been found comparing the efficacy of topical clobetasol with intralesional triamcinolone in the treatment of hand eczema. Here, severity of hand eczema (HECSI score) reduced gradually in both intralesional triamcinolone treated group and topical clobetasol treated group but the rate was significantly higher in clobetasol treated group $(\mathrm{p}<0.050)$. Regarding the adverse reaction thinning of skin was seen in 10.0 and $16.7 \%$ patients in group A and B respectively ( $p>0.050)$. Alcers (1980) has shown that the common risk of long-term use of topical potent steroid is thinning of skin. 7 Here, thinning of the skin with topical clobetasol propionate is comparable with that of intralesional triamcinolone acetonide.

\section{Conclusion}

Intralesional triamcinolone acetonide is effective in the treatment of hand eczema but efficacy is significantly less than that of topical clobetasol propionate with comparable safety.

\section{Conflict of interest}

There was no conflict of interest.

\section{References}

1. Coenraads PJ. Hand eczema. N Engl J Med. 2012; 367: 1829-37.
2. Thyssen JP, Johansen JD, Linneberg A, Menne T. The epidemiology of hand eczema in the general population: Prevalence and main findings. Contact Dermat. 2010; 62: 75-87.

3. Menne T, Johansen JD, Sommerlund M, Veien NK. Hand eczema guidelines based on the Danish guidelines for the diagnosis and treatment of hand eczema. Contact Dermat. 2011; 65: 3-12.

4. Peterkin GAG, Morley WN, Chalmers D Triamcinolone and flucinolone ointment in atopic eczema. Br Med J. 1962; 1: 1392.

5. Holden CA, Berth-Jones J. Eczema, lichenificatiln, prurigo and rythroderma. In: Rooks Textbook of dermatology. Burns $\mathrm{T}$, Breathnach S, Cox N, Griffith C (eds). $7^{\text {th }}$ ed. London, Blackwell Publishing, 2004, pp 1-55.

6. Veien NK, Olholm Larsens, Thestrup-Pedersen K, Schou G. Long-term, intermittent treatment of chronic hand cezema with mometasone furoate. $\mathrm{Br}$ J Dermatol. 1999; 140: 882-86.

7. Alcers WA. Risks of unoccluded topical steroids in clinical trials. Arch Dermatol. 1980; 16: 786-38.

8. Schimmer B, Parker K. Adrenocorticotropic hormone; adrenocortical steroids and their synthetic analogs; inhibitors of the synthesis and actions of adrenocortical hormones. In: Goodman and Gilman's The pharmacological basis of therapeutics. Hardman JG, Limbird LE (eds). 10th ed. New York, McGraw-Hill, 2001, pp 1649-77.

9. Firooz A, Tehranchi-Nia Z, Ahmed AR. Benefits and risks of intralesional corticosteroid injection in the treatment of dermatological diseases. Clin Exp Dermatol. 1995; 20: 363-70.

10. Held E, Skoet R, Johansen JD, Agner T The hand eczema severity index (HECSI): A scoring system for clinical assessment of hand eczema. A study of inter- and intraobserver reliability. $\mathrm{Br} J$ Dermatol. 2005; 152: 302-07.

11. Islam M, Ali M, Wahab M, Khondker L, Siddique M. Efficacy of topical mometasone furoate $0.1 \%$ cream in the treatment of atopic dermatitis. Med Today. 2014; 26: 36-40.

12. Möller H, Svartholm H, Dahl G. Intermittent maintenance therapy in chronic hand eczema with clobetasol propionate and flupredniden acetate. Curr Med Res Opin. 1983; 8: 640-44. 